\title{
Radioactive lodine Remnant Ablation: The Beta-knife Completion Thyroidectomy
}

\author{
Raydoaktif lyot Bakiye Doku Ablasyonu: Beta-knife Tamamlayııı Tiroidektomisi
}

\author{
Seza Gulec, MD, FACSI, Russ Kuker, MD2
}

I Florida International University Herbert Wertheim College of Medicine, Departments of Surgery and Nuclear Medicine, Miami, USA

2University of Miami Miller School of Medicine, Department of Radiology, Miami, USA

\begin{abstract}
The rationale and objectives for radioactive iodine (RAI) ablation remain perplexing to many. This review addresses the meaning, clinical context and the goals of "ablation": the RAl treatment after a total thyroidectomy. This article also aims to clarify the definition of a total thyroidectomy and how a thyroid remnant can introduce a confounding factor in the postoperative management of patients with differentiated thyroid cancer. The implications of an existing thyroid remnant on RAl diagnostic imaging and serum thyroglobulin levels are discussed. This review provides a rational approach validating the utility of RAI remnant ablation regardless of the patient's risk stratification.

Keywords: Radioactive iodine, ablation, thyroid cancer, thyroid remnant, I-131, I-124, dosimetry, beta knife
\end{abstract}

\section{Öz}

Radyoaktif iyot (RAi) ablasyon kavramı mantığının ve hedeflerinin birçok kişi için hala yeterince açık olmadığını görüyoruz. Bu makalede total tiroidektomiyi takiben yapılan RAi "ablasyon" girişiminin anlamı, hedefleri ve klinik değeri izah edilmektedir. Gerçekçi anlamda total tiroidektominin RAi ablasyonu ile mümkün olduğu tezini savunuyor ve destekleyen verileri sistematik olarak sunuyoruz.

Anahtar kelimeler: Radyoaktif iyot, ablasyon, tiroid kanseri, bakiye tiroid dokusu, I-131, I-124, dozimetri, beta knife

\section{Introduction}

The role for radioactive iodine (RAI) in the management of metastatic differentiated thyroid cancer (DTC) is indisputable. Its utilization postoperatively as part of initial treatment, however, is still a matter of debate. The 2015 American Thyroid Association (ATA) guidelines is a 133-page document written in a dissertation format (1).
The rationale for each recommendation is discussed, in detail, in a scholarly fashion, but yet, there is a sense of ambiguity in defining the indications for administration of RAl ablation. This review will discuss the ATA recommendations from a perspective that accounts surgical considerations, nuclear medicine principles, and genomic developments.

Address for Correspondence: Seza Gulec, MD, FACS, Florida International University Herbert Wertheim College of Medicine, Departments of Surgery and Nuclear Medicine, Miami, USA

Phone: (786) 6930821 E-mail: sgulec@fiu.edu 
The Role of RAI (Including Remnant Ablation, Adjuvant Therapy, or Therapy for Persistent Disease) after Thyroidectomy in the Primary Management of Differentiated Thyroid Cancer

\section{ATA Recommendation 51}

A) RAI remnant ablation is not routinely recommended after thyroidectomy for ATA low-risk DTC patients. Consideration of specific features of the individual patient that could modulate recurrence risk, disease follow-up implications, and patient preferences are relevant to RAl decision-making (Weak recommendation, low-quality evidence).

B) RAI remnant ablation is not routinely recommended after lobectomy or total thyroidectomy for patients with unifocal papillary microcarcinoma, in the absence of other adverse features (Strong recommendation, moderate-quality evidence).

C) RAI remnant ablation is not routinely recommended after thyroidectomy for patients with multifocal papillary microcarcinoma in the absence of other adverse features. Consideration of specific features of the individual patient that could modulate recurrence risk, disease follow-up implications, and patient preferences are relevant to RAI decision-making (Weak recommendation, low-quality evidence).

D) RAI adjuvant therapy should be considered after total thyroidectomy in ATA intermediate-risk level DTC patients (Weak recommendation, low-quality evidence).

E) RAl adjuvant therapy is routinely recommended after total thyroidectomy for ATA high-risk DTC patients (Strong recommendation, moderate-quality evidence).

RAl treatment is given in three distinct settings with different clinical indications (intents);

1) Ablation of the remnant

2) Adjuvant treatment for residual disease or occult metastatic disease

3) Therapy for known metastatic disease.

The term "ablation" specifically refers to first-line RAI treatment after surgical total thyroidectomy.

The specific target of this treatment is normal residual thyroid tissue, i.e. the remnant, (Table 1). The confusion regarding the indications of RAI ablation stems from the underestimation of the impact of the remnant volume and patterns of uptake on imaging studies following surgical total thyroidectomy. Certain surgical details need to be explained in order to clarify the remnant concept from a clinical context.

\section{Surgical Anatomy of Total Thyroidectomy, Sources and Locations of Thyroid Remnants}

The strict definition of total thyroidectomy, as it pertains to subsequent diagnostic and therapeutic considerations, is the removal of all functioning thyroid tissue. When a clinical decision is made for a lobectomy, based on a low risk disease designation, "ablation" is not part of the equation. Ablation is, in the most simplistic terms, the eradication of all functional thyroid tissue left behind after surgical total thyroidectomy. A surgical total thyroidectomy entails removing the gland in the plane outside its "true capsule" (Figure 1). The true capsule is a very fine layer. A faithful dissection over the true capsule may occasionally pose a significant challenge to the viable preservation of the parathyroid glands and safe protection of the recurrent laryngeal nerve $(R L N)$, as these critical structures have very intimate anatomic relations with the true capsule (Figure 2). A rational definition of total thyroidectomy is, therefore, the removal of the anatomical gland with viable and non-traumatic preservation of the parathyroid glands and RLN. It is important to emphasize that injuries to these critical structures are usually caused by ischemia resulting from devascularization, or traumatic contusion due to vigorous dissection and traction, not necessarily inadvertent transection or resection. A safe dissection, when performed in a cognizant way, may result (or even require) entering inside the true capsule and leaving a focal, thin rim of functional thyroid tissue in situ. A similar challenge may be encountered dissecting the upper pole vessels. There is an intimate relationship between the external branch of the superior laryngeal nerve and the superior thyroidal artery and vein. The dissection of the thyroid upper pole can also be challenging, particularly with a high-riding position. A safe division of the upper pole vasculature could leave behind a small remnant

Table 1. Radioactive iodine treatment objectives

\begin{tabular}{|c|c|c|}
\hline $\begin{array}{l}\text { RAI treatment } \\
\text { intent }\end{array}$ & Target & Objectives \\
\hline Ablation & Remnant & $\begin{array}{l}\text { Increase specificity of } \\
\text { Tg monitoring } \\
\text { Complete post- } \\
\text { surgical staging } \\
\text { Identify/clear } \\
\text { ambiguous foci of } \\
\text { uptake }\end{array}$ \\
\hline Adjuvant treatment & $\begin{array}{l}\text { Residual disease } \\
\text { Recurrent disease } \\
\text { Metastatic disease }\end{array}$ & $\begin{array}{l}\text { Ablation objectives } \\
\text { Disease control }\end{array}$ \\
\hline Therapy & $\begin{array}{l}\text { Residual disease } \\
\text { Recurrent disease } \\
\text { Metastatic disease }\end{array}$ & Disease control \\
\hline
\end{tabular}




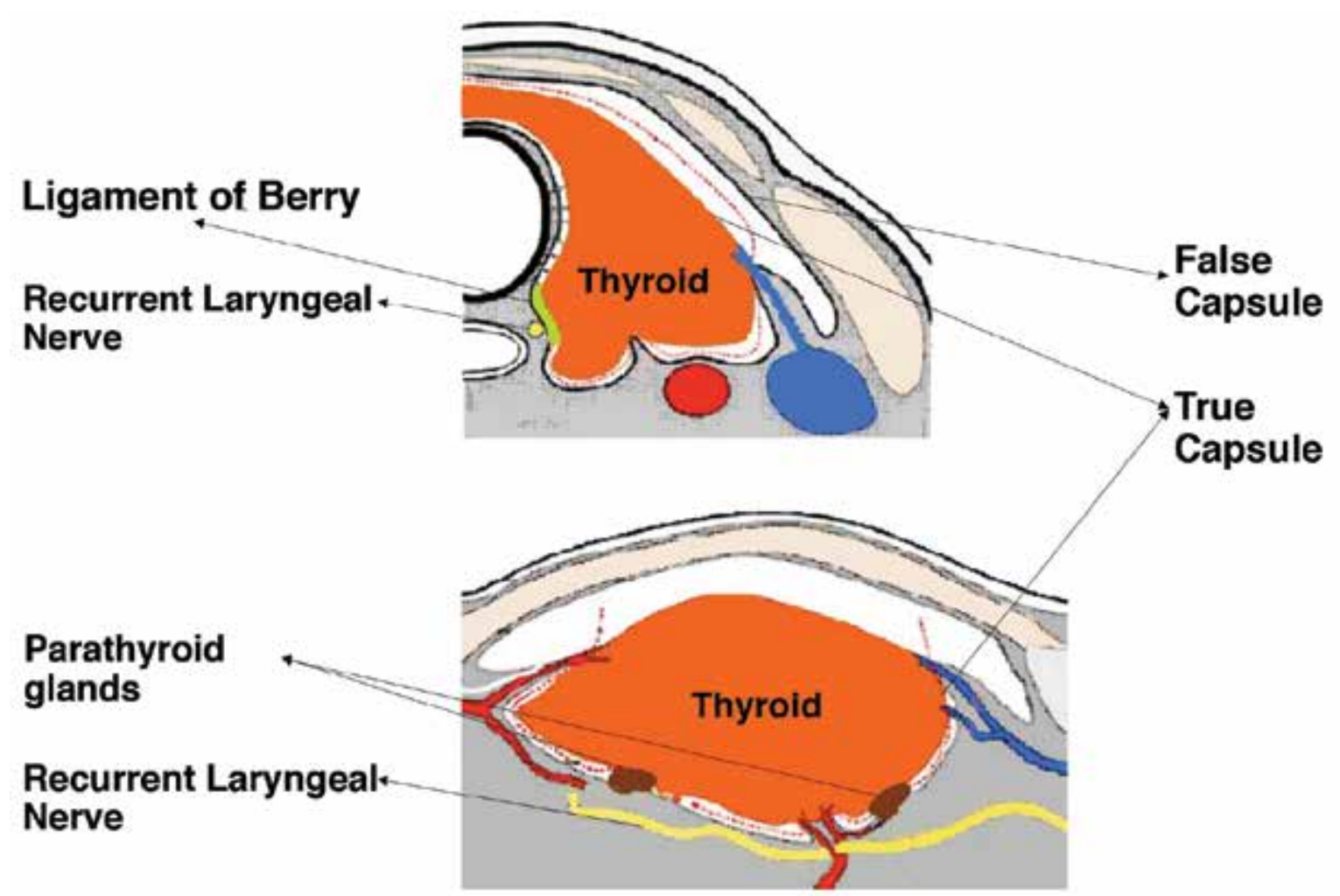

Figure 1. The surgical anatomy and technique of total thyroidectomy, remnant volume. This diagram adapted from Tan et al. (7) shows the fascial compartments in the thyroid space. The parathyroid glands are situated over the true capsule. The separation of the parathyroid glands off the true capsule can disrupt the vascular supply. The cranial end of the recurrent laryngeal nerve typically travels under the ligament of Berry and, at this position, is very close to the true capsule of the thyroid. A vigorous extracapsular dissection may traumatize these vital structures even if they are carefully identified and avoided during surgery
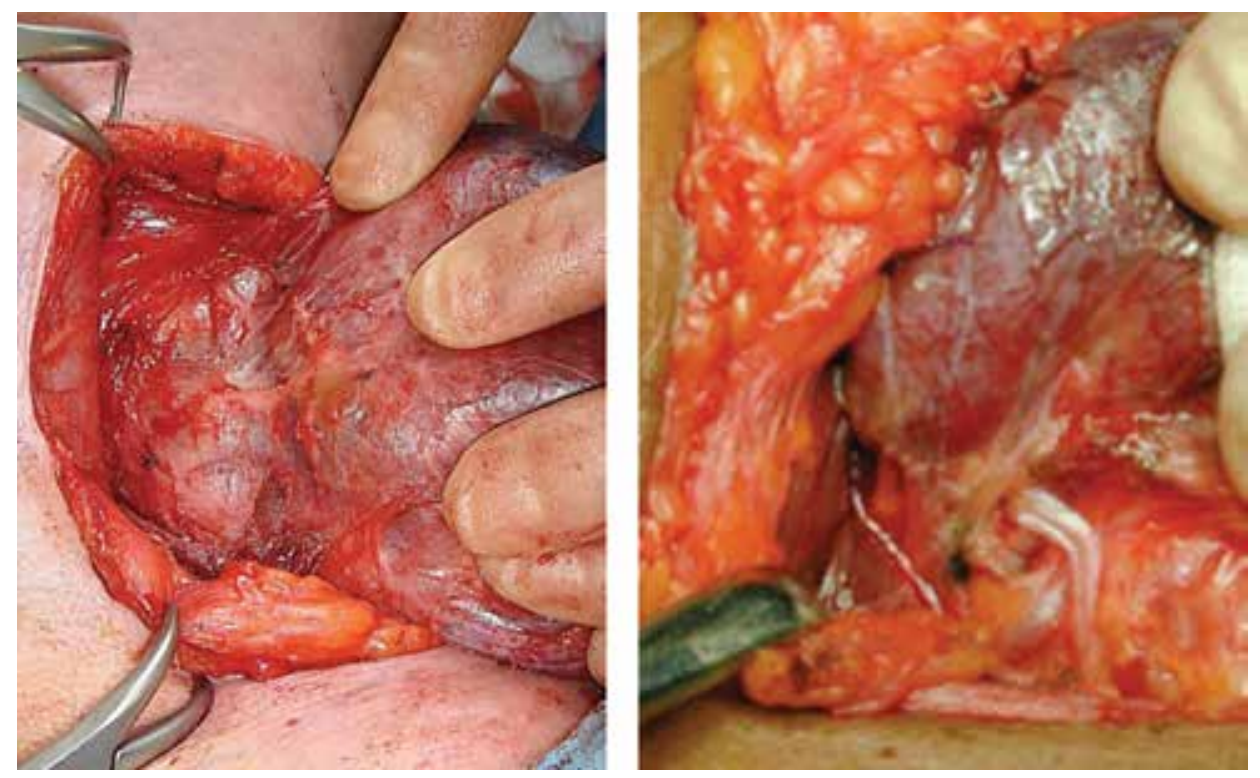

Figure 2. The image on the left shows a parathyroid gland lying on the thyroid capsule. The image on the right shows the recurrent laryngeal nerve under the ligament of Berry, and their very intimate relations with the true capsule of the thyroid gland 
(Figure 3). The pyramidal lobe usually has a short extension containing functional tissue that becomes a fibrotic cord as it extends cranially. It is typically divided at a reasonable length along its tract. Occasionally this pyramidal cord may also contain functioning thyroid tissue. The totality of a total thyroidectomy is reliant on the surgeon's technique. High volume experienced surgeons can produce consistent results in terms of low remnant volume; however, the reality in community settings could vary widely. The terms near-total or subtotal thyroidectomy are disclosures of not insignificant remnant volume. Remnant thyroidectomy is accomplished by RAl ablation.

\section{Radioactive lodine Ablation: Beta-knife Completion Thyroidectomy}

The therapeutic effect of I-131 works through beta particles, thus, it has been named a "beta-knife" (2). The objectives of ablation are three-fold a) Ablation eradicates all functioning thyroid tissue. With that goal accomplished, thyroglobulin ( $\mathrm{Tg}$ ) becomes a highly specific tumor marker. This simply facilitates the postop long-term patient follow-up. b) Ablation wipes out all focal normal thyroid tissue left in-situ by the surgeon to avoid injury to laryngeal nerves and parathyroid glands. From a surgical standpoint, these small clusters of normal thyroid tissue remnants are inconsequential; however, they appear as focal areas of RAl uptake on future imaging studies and can easily be interpreted as

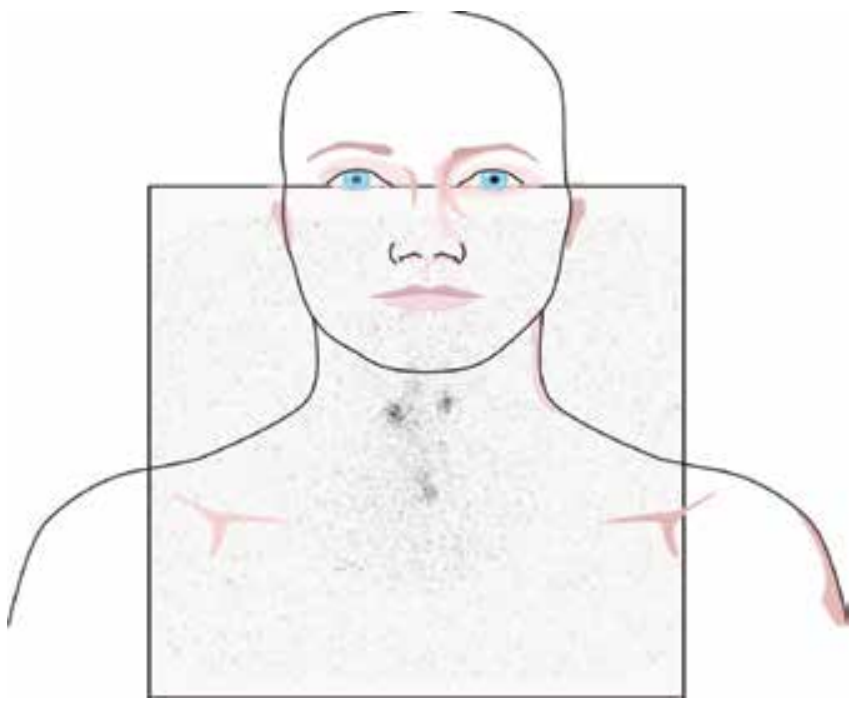

Figure 3. Normal postoperative radioactive iodine scan. This image shows a small focus of activity at the midline of the lower neck compatible with a midline remnant. There are also two small foci of radioactive iodine uptake in the upper neck, which are equivocal. Upon referring with the surgeon who performed the operation, these foci were confirmed to represent remnant activity beneath the superior parathyroid glands. Without knowledge of the operative findings these can easily be reported as metastatic nodal disease metastatic disease. Eradication of these potential sources of misdiagnosis, while there is still open communication between the surgeon and the imager, is important. c) The post-ablation whole-body scan is considered the standard for extent of disease evaluation.

When postoperative RAl treatment is contemplated with an adjuvant intent, in addition to the remnant ablation objectives, RAl is aimed to target residual disease or occult metastatic disease. When the intent is adjuvant treatment, risk stratification becomes important in the selection of the administered activity of $\mathrm{I}-131$. For remnant ablation purposes only, the risk stratification has no bearing. Complete thyroidectomy, in the strictest sense, is only possible with surgical (cold steel knife) thyroidectomy, followed by I-131 ablation (beta knife). There exists a group of patients where surgical total thyroidectomy removes all the functional remnant tissue. Although it could be argued that RAI ablation is not necessary in this group, it is challenging to identify these patients using standard clinical evaluations.

\section{Challenges and Potential Solutions for Accurate Assessment of Remnant Volume}

The volume of the thyroid remnant is highly variable and is dependent on the surgeon's technique; it is not typically highlighted in the operative report and is usually undetectable by ultrasound (US) or other anatomic imaging modalities such as computed tomography (CT) or magnetic resonance imaging (MRI). Serum $\mathrm{Tg}$ can provide some information as to the presence of functioning thyroid tissue; but the marked variability in Tg levels, which can overlap with metastatic disease, makes $\mathrm{Tg}$ an unreliable quantitative measure of remnant volume. Occult metastatic sites may only be detected by a post-ablation scan. Typical 1-5 mCi l-131 imaging has notoriously low sensitivity for disclosing occult foci.

Postoperative/pre-ablative RAl imaging may be considered to determine the extent of residual functional thyroid tissue, or remnant volume. I-131 has become the mainstay for RAI imaging due to its availability and relatively low cost; however, one must recognize the inherent limitations of $\mathrm{I}-131$ as a diagnostic imaging agent. I-131 has high energy gamma emissions with the greatest abundance of $364 \mathrm{keV}$ which lead to septal penetration and limit the spatial resolution of standard gamma cameras. In addition, only low administered activities of I-131 can be given for diagnostic purposes due to concerns for stunning, especially when subsequent RAl treatment is being considered. Routine diagnostic I-131 scans are usually performed with administered activities in the range of $1-5 \mathrm{mCi}$. These low dose images are often of limited diagnostic quality and may underestimate the extent of disease evaluation. Subtle or non-visualized foci of RAl avid disease on low dose 
diagnostic I-131 scans may become evident on posttreatment scans with therapeutic administered activities (Figure 4). Even with higher administered activities of 1-131, it can be difficult to differentiate foci of uptake in the neck as thyroid remnants versus nodal metastatic disease. RAl avid foci in the neck can be elucidated with increased confidence only after the thyroid remnant has been completely ablated. In addition, eliminating the remnant comprised of highly avid normal thyroid tissue reduces competition for RAl at metastatic sites thereby enhancing diagnostic scan sensitivity and therapeutic efficacy (3).

Although not in routine clinical use currently, l-124 imaging has been demonstrated to be a very sensitive functional imaging agent. I-124 positron emission tomography (PET)/ CT has an outstanding spatial resolution in elucidating small thyroid remnants from the right or left lobes or in the distribution of the pyramidal lobe (Figure 5). Due to its anatomic precision, I-124 PET/CT can also distinguish
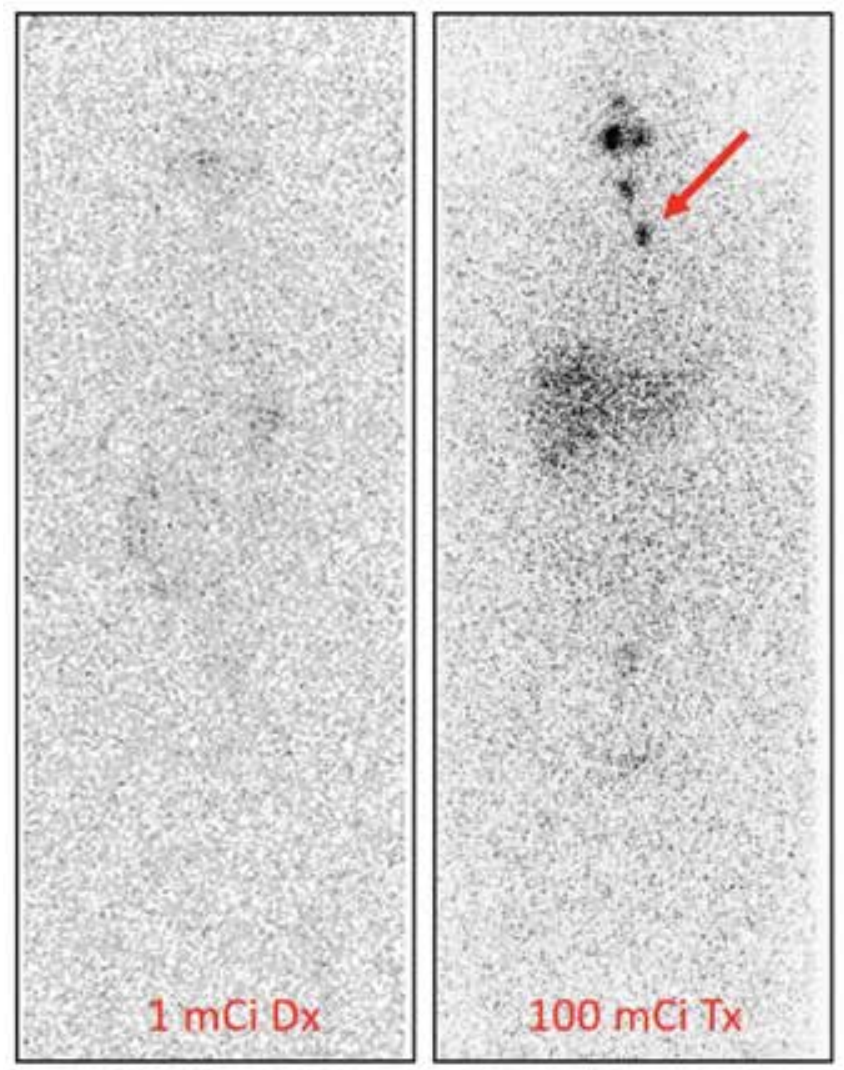

Figure 4. Radioactive iodine (RAl) scan with $1 \mathrm{mCi}$ versus $100 \mathrm{mCi}$ demonstrating occult remnant or nodal disease. The image on the left is a diagnostic whole body scan with $1 \mathrm{mCi}$ of $\mathrm{I}-131$ showing no abnormal RAl avid foci in the neck. The image on the right is a posttreatment scan for the same patient after therapy with $100 \mathrm{mCi}$ of I-131. This image shows physiologic activity in the salivary glands as well as two RAI avid foci in the neck that were confirmed to represent nodal metastases nodal uptake from a remnant in the thyroid bed which may not be adequately visualized with other imaging modalities. I-124 has been shown to have a similar performance in detection of RAl avid lesions as compared to posttherapeutic I-131 scans. Additionally, the risk of stunning at higher administered activities of I-131 may not be observed with I-124. Therefore, I-124 may be considered the most sensitive imaging modality for assessing remnant thyroid tissue.

Perhaps the greatest merit of I-124 PET/CT is that it allows accurate quantitation of remnant volume and kinetics for the purposes of remnant dosimetry. Our group showed significant variations in cumulated activities and functional volumes of thyroid remnants between cohort patients. The maximum remnant activity ranged from 1.2 to 215.9 $\mathrm{uCi}$ with the total functional remnant volume (the total number of voxels within the remnant range of interest) ranging from 1 to $60 \mathrm{~mL}$. The activity per volume of remnant tissue ranged from 0.036 to $11.265 \mathrm{uCi} / \mathrm{mL}$. The total cumulated activity within the remnant ranged from 68 to $12757.3 \mathrm{uCi} / \mathrm{hr}(4)$. This variability highlights how a thyroid remnant may become a confounding factor in the postoperative management of DTC patients and why RAl ablation is key to maintaining a standard baseline for which future imaging and laboratory parameters can be compared.

\section{Specificity of Thyroglobulin}

$\mathrm{Tg}$ is a highly specific tumor marker when functioning thyroid tissue is no longer present, i.e. after total thyroidectomy and RAI ablation of the remnant. It has been estimated that $1 \mathrm{~g}$ of normal thyroid tissue releases about $1 \mathrm{ng} / \mathrm{mL}$ of $\mathrm{Tg}$ into the serum when thyroidstimulating hormone (TSH) is normal and about $0.5 \mathrm{ng} /$ $\mathrm{mL}$ when TSH is suppressed ( $<0.1 \mathrm{mIU} / \mathrm{L})(5)$. The remnant volume, and thus remnant-produced $\mathrm{Tg}$, is dependent on the surgical technique and potentially could be highly variable/unpredictable.

The factors influencing baseline and recombinant human TSH stimulated Tg levels in patients with metastatic DTC were investigated in a study by Robbins et al. (6). The authors found wide variations in Tg levels and considerable overlap between metastatic sites. The median baseline $\mathrm{Tg}$ level for cervical metastases was $2 \mathrm{ng} / \mathrm{mL}$ and increased to a median of $8 \mathrm{ng} / \mathrm{mL}$ after recombinant human TSH stimulation. The median baseline and stimulated Tg levels for mediastinal metastases were $4 \mathrm{ng} / \mathrm{mL}$ and $16 \mathrm{ng} / \mathrm{mL}$, and for distant metastatic sites were $25 \mathrm{ng} / \mathrm{mL}$ and 180 $\mathrm{ng} / \mathrm{mL}$, respectively. The patients with thyroid remnants included in the study had a median baseline $\mathrm{Tg}$ level of $0.6 \mathrm{ng} / \mathrm{mL}$, with the highest being $66 \mathrm{ng} / \mathrm{mL}$. After recombinant human $\mathrm{TSH}$, the median stimulated $\mathrm{Tg}$ in patients with thyroid remnants was $1.2 \mathrm{ng} / \mathrm{mL}$ but ranged as high as $250 \mathrm{ng} / \mathrm{mL}$. 
Following $\mathrm{Tg}$ levels in patients who have undergone total thyroidectomy but not RAl ablation is challenging. The Tg level is expected to increase by at least twofold in the presence of a thyroid remnant under the influence of recombinant human TSH; however, the stimulated Tg level has been shown to increase almost four-fold in some patients. The inconsistent baseline $\mathrm{Tg}$ levels produced by the remnant along with the documented variability in stimulated $\mathrm{Tg}$ levels that overlap with metastatic disease make it very difficult to reliably detect occult metastasis. In addition, the natural progression of an un-ablated thyroid remnant under TSH suppression and its effect on Tg production are not clearly established. These issues can be avoided if the thyroid remnant is ablated with RAI thereby eradicating all functioning thyroid tissue and rendering $\mathrm{Tg}$ a very specific indicator of recurrent disease in post-surgical patients.

\section{The Activity of I-131 to be Used for Remnant Ablation or Adjuvant Therapy}

\section{ATA Recommendation 55}

A) If RAl remnant ablation is performed after total thyroidectomy for ATA low-risk thyroid cancer or intermediate-risk disease with lower risk features (i.e., low-volume central neck nodal metastases with no other known gross residual disease or any other adverse features), a low administered activity of approximately of $30 \mathrm{mCi}$ is generally favored over higher administered activities (Strong recommendation, highquality evidence).

B) Higher administered activities may need to be considered for patients receiving less than a total or near-total thyroidectomy in which a larger remnant is suspected or in which adjuvant therapy is intended (Weak recommendation, low-quality evidence).

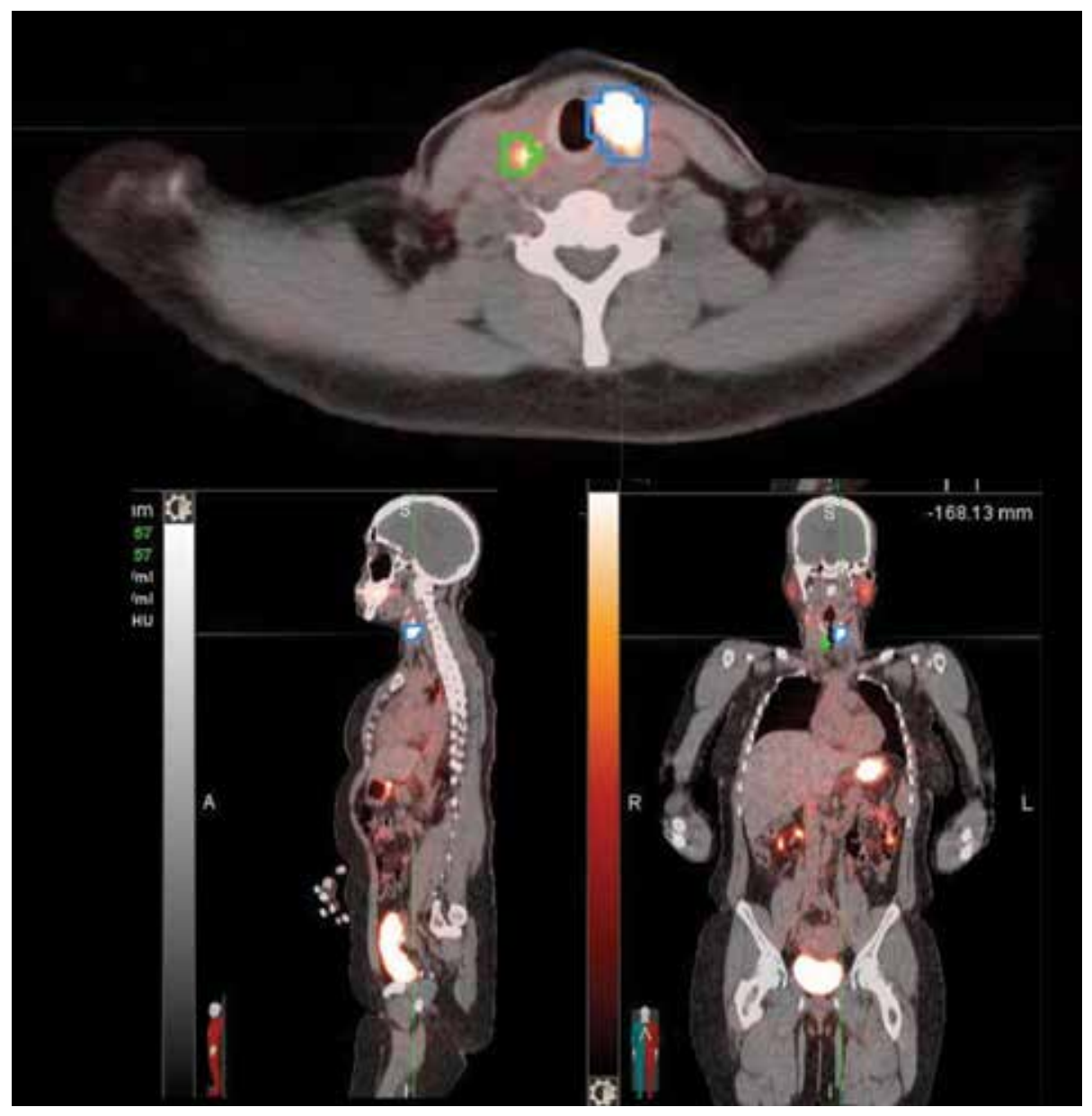

Figure 5. I-124 positron emission tomography/computed tomography image through the level of the thyroid bed shows regions of interest drawn around a thyroid remnant (blue) and a metastatic right level 3 lymph node (green). The remnant is not measurable by ultrasound or computed tomography. There is overestimation of functional volume (correctible) due to voxel saturation phenomenon 


\section{ATA Recommendation 56}

\section{Administered RAl Activity $(\mathrm{mCi})$ and Radiation} Absorbed Dose (Rad) Relationship

When RAl is intended for initial adjuvant therapy to treat suspected microscopic residual disease, administered activities above those used for remnant ablation up to $150 \mathrm{mCi}$ are generally recommended (in absence of known distant metastases). It is uncertain whether routine use of higher administered activities $(>150 \mathrm{mCi})$ in this setting will reduce structural disease recurrence for T3 and N1 disease (Weak recommendation, low-quality evidence).

Currently, the most common practice in RAI ablation is to use a fixed amount of radioiodine regardless of the size of the thyroid remnant or the percentage of radioiodine uptake. Different administered activity levels have been tested over the years ranging from $30 \mathrm{mCi}$ to $150 \mathrm{mCi}$. There has been a paradigm shift towards using less administered activities for RAl remnant ablation in the setting of low-risk DTC since the publication of two high-impact articles in the New England Journal of Medicine in 2012, and further propagated after release of the 2015 ATA guidelines $(8,9)$. As paradoxical as it may seem, $30 \mathrm{mCi}$ of radioiodine will completely destroy the thyroid remnant in some patients whereas $150 \mathrm{mCi}$ may not be sufficient in others. The explanation is that, there is no linear relationship between the administered activity and radiation absorbed dose to the remnant. The radiation dose (in rads) depends not only on the number of millicuries administered, but also the percent uptake, the size of the remnant, and the effective half-life $\left(T_{1 / 2}\right.$ eff) of I-131 in the remnant. Patients with small remnants and high uptakes may receive a large radiation dose from $30 \mathrm{mCi}$ whereas those with large remnants and low uptakes may receive a small and inadequate radiation dose from $150 \mathrm{mCi}$. In a 1983 dosimetric study, Becker and Hurley demonstrated a wide variation in uptake and remnant size in patients who were referred for ablation (10). There was no correlation between the number of millicuries administered and the radiation absorbed dose delivered to the remnant (Figure 6). Although this study unarguably demonstrated the unreliability of a fixed or standard amount of radioiodine for ablation, due to feasibility and logistical considerations a dosimetric approach never was adapted.

There is a clear need to develop individualized dosimetryguided RAI ablation protocols. I-124 PET/CT offers a robust quantitative tool to achieve this goal. Active studies are being performed to determine the technical prerequisites for a time and cost-conscious standard protocol.

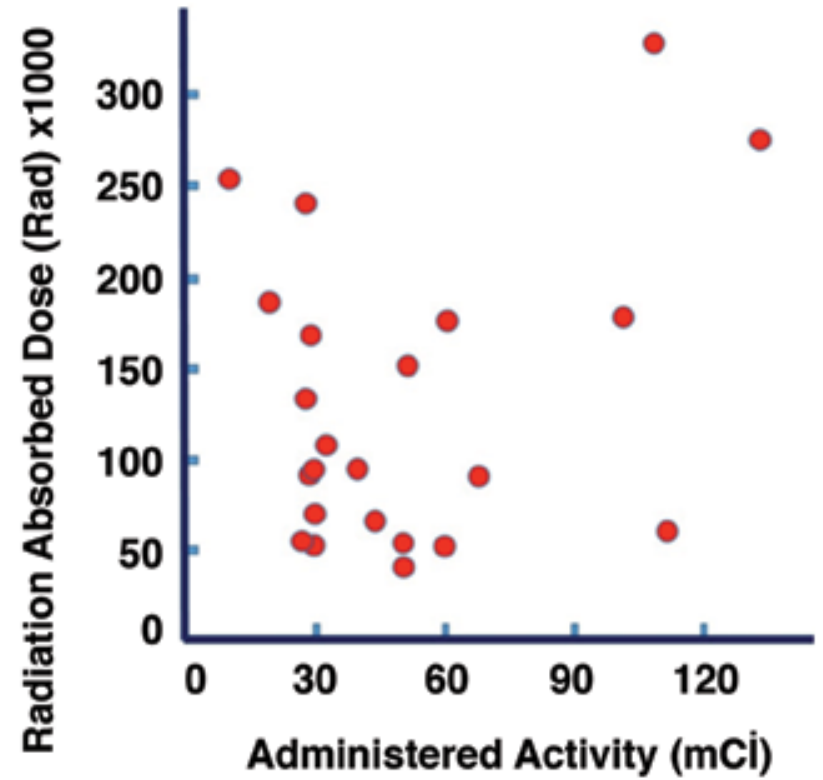

Figure 6. Lack of correlation between radiation dose to the remnant and millicuries of radioactive iodine administered. Adapted from (10) Hurley JR, Becker DV. The use of radioiodine in the management of thyroid cancer. Freeman LM, Weissman HS (eds). Nuclear Medicine Annual. New York, Raven Press 1983;329-384.

\section{Summary and Recommendations}

Although the potential side effects of RAl are real and efforts to utilize lower administered activities for ablation are commendable, this should not overlook the opportunity for achieving complete ablation. The benefits of complete remnant ablation in the future follow-up and management of DTC patients after thyroidectomy cannot be denied. From a practical standpoint, a total thyroidectomy usually leaves behind some functioning thyroid tissue. This postsurgical thyroid remnant cannot be accurately evaluated/visualized with anatomic imaging studies like CT or ultrasound, and it can be misleading on functional RAI imaging indistinguishable from RAI avid disease in the neck. Moreover, the volume of remaining thyroid tissue is dependent upon the surgical technique and invariably and unpredictably affects the $\mathrm{Tg}$ level at baseline and under TSH stimulation. Avoiding RAI remnant ablation because of the risk of side effects or the reliance on underpowered, short-term prospective studies or flawed retrospective analyses fails to recognize the goals of therapy and the practical approach to the postoperative follow-up of DTC patients. The therapeutic administration of RAI to ablate the thyroid remnant allows for completion of a "true" total thyroidectomy (cold steel knife + beta knife) and improves the postoperative management of DTC patients by facilitating RAI imaging and permitting the use of serum Tg as a highly specific tumor marker. 
Mol Imaging Radionucl Ther 2017;26(Suppl 1):16-23 Gulec and Kuker. RAI Remnant Ablation: The Beta-knife Completion Thyroidectomy

The recommendations below incorporate genomic profiling for risk stratification and dosimetric approach for selection of administered activities for RAl ablation.

\section{Proposed Guidelines for RAI Ablation}

A) RAl ablation decision should be made at the time of the surgical treatment decision. Risk stratification should include genomic profiling. RAI remnant ablation is routinely recommended after total thyroidectomy, if the preoperative intent was total elimination of anatomic and functional thyroid tissue. Main consideration is the role for Tg monitoring and RAI imaging surveillance in the long-term management of patients. RAl ablation should be administered with radiation absorbed dose to the remnant tissue optimized.

B) If micropapillary cancer was incidentally reported in the surgical pathology following a total thyroidectomy, RAI ablation may be omitted if there is no histopathologic or genomic risk factor identified.

C) RAI remnant ablation is not indicated after lobectomy. If a histopathologic or genomic risk factor is identified, a completion thyroidectomy should be performed and followed by RAl ablation.

D) If the clinical intent is adjuvant treatment for suspected/known residual/metastatic disease RAI ablation should be administered in a therapeutic context, with radiation absorbed dose to the malignant disease optimized.

E) Administered activity selection should be determined based on dosimetric considerations, for both remnant ablation and adjuvant treatment indications.

\section{Authorship Contributions}

Surgical and Medical Practices: Seza Gulec, Russ Kuker, Concept: Seza Gulec, Russ Kuker, Design: Seza Gulec, Russ Kuker, Data Collection or Processing: Seza Gulec, Russ Kuker, Analysis or Interpretation: Seza Gulec, Russ Kuker, Literature Search: Seza Gulec, Russ Kuker, Writing: Seza Gulec, Russ Kuker.
Conflict of Interest: No conflict of interest was declared by the authors.

Financial Disclosure: The authors declared that this study has received no financial support

\section{References}

1. Haugen BR, Alexander EK, Bible KC, Doherty GM, Mandel SJ, Nikiforov YE, Pacini F, Randolph GW, Sawka AM, Schlumberger M, Schuff KG, Sherman SI, Sosa JA, Steward DL, Tuttle RM, Wartofsky L. 2015 American Thyroid Association Management Guidelines for Adult Patients with Thyroid Nodules and Differentiated Thyroid Cancer: The American Thyroid Association Guidelines Task Force on Thyroid Nodules and Differentiated Thyroid Cancer. Thyroid 2016;26:1-133.

2. Gulec SA. The Art and Science of Thyroid Surgery 100 Years after Theodor Kocher Moving into the Age of Genomics: A Personal Insight. Mol Imaging Radionucl Ther 2016.

3. Ain KB. Radioiodine-remnant ablation in low-risk differentiated thyroid cancer: pros. Endocrine 2015;50:61-66.

4. Gulec SA, Kuker RA, Goryawala M, Fernandez C, Perez R, KhanGhany A, Apaza A, Harja E, Harrell M. (124)I PET/CT in Patients with Differentiated Thyroid Cancer: Clinical and Quantitative Image Analysis. Thyroid 2016:26:441-448.

5. Wartofsky L, Van Nostrand D. Thyroid Cancer: A Comprehensive Guide to Clinical Management. Totowa, NJ: Humana Press Inc 2006

6. Robbins RJ, Srivastava S, Shaha A, Ghossein R, Larson SM, Fleisher $M$, Tuttle RM. Factors influencing the basal and recombinant human thyrotropin-stimulated serum thyroglobulin in patients with metastatic thyroid carcinoma. J Clin Endocrinol Metab 2004;89:60106016.

7. Tan YH, Du GN, Xiao YG, Guo SQ, Wu T, Chen PZ, Yan GB, Tan DX, Wang K. The false thyroid capsule: new findings. J Laryngol Otol 2013;127:897-901

8. Schlumberger M, Catargi B, Borget I, Deandreis D, Zerdoud S, Bridji B, Bardet S, Leenhardt L, Bastie D, Schvartz C, Vera P, Morel O, Benisvy D, Bournaud C, Bonichon F, Dejax C, Toubert ME, Leboulleux S, Ricard M, Benhamou E, Tumeurs de la Thyroide Refractaires Network for the Essai Stimulation Ablation Equivalence T. Strategies of radioiodine ablation in patients with low-risk thyroid cancer. N Engl J Med 2012;366:1663-1673.

9. Mallick U, Harmer C, Yap B, Wadsley J, Clarke S, Moss L, Nicol A, Clark $P M$, Farnell K, McCready R, Smellie J, Franklyn JA, John R, Nutting CM, Newbold K, Lemon C, Gerrard G, Abdel-Hamid A, Hardman J, Macias E, Roques T, Whitaker S, Vijayan R, Alvarez P, Beare S, Forsyth $\mathrm{S}$, Kadalayil L, Hackshaw A. Ablation with low-dose radioiodine and thyrotropin alfa in thyroid cancer. N Engl J Med 2012;366:16741685.

10. Hurley JR, Becker DV. The use of radioiodine in the management of thyroid cancer. Nuclear Medicine Annual. New York, Raven Press 1983;329-384. 